\title{
PART I: OPTIMIZATION OF HYDRALAZINE HYDROCHLORIDE IMMEDIATE RELEASE LAYER IN ANTIHYPERTENSIVE BILAYER TABLET
}

\author{
HARSH TRIVEDI ${ }^{*}$, KUNAL PATEL ${ }^{2}$, NISHANT A. OZA ${ }^{3}$, SWATI SAGAR ${ }^{4}$
}

\author{
${ }^{1,2}$ Shree Swaminarayan Sanskar Pharmacy College, Zundal, Gandhinagar, Gujarat, India, ${ }^{3,4} \mathrm{C}$. U. Shah University, Wadhwan City, Gujarat, \\ India-363030. \\ Email: harshtrivedi28@gmail.com \\ Received: 30 Apr 2020, Revised and Accepted: 07 Jul 2020
}

\begin{abstract}
Objective: Aim of the present study was the optimization of the immediate release (IR) layer containing hydralazine hydrochloride (HHC) $25 \mathrm{mg}$ and compressed with a sustained-release (SR) layer of isosorbide dinitrate (ISDN) $40 \mathrm{mg}$ to decrease the dosing frequency.

Methods: In this study, Drug-excipients compatibility study was carried out by FT-IR and a preliminary trial was conducted for screening of super disintegrating agents. The amount of sodium starch glycolate (SSG) $\left(\mathrm{X}_{1}\right)$ and the amount of ac-di-sol ${ }^{8}\left(\mathrm{X}_{2}\right)$ was chosen as independent variables in $3^{2}$ full factorial design while wetting time (WT) $\left(\mathrm{Y}_{1}\right)$, disintegration time (DT) $\left(\mathrm{Y}_{2}\right)$ and In vitro drug release at 15 min $\left(\mathrm{Q}_{15}\right)\left(\mathrm{Y}_{3}\right)$ were taken as dependent variables. Multiple linear regression analysis, ANOVA, and graphical representation of the influence of factor by 3D plots were performed by using sigma plot 13.0. In the present study, the following constraints were used for the selection of an optimized batch: WT $<16 \mathrm{~s}$, DT<25 s, and $\mathrm{Q}_{15}>90 \%$. To validate the evolved mathematical models, a checkpoint batch was selected from its desirability value.
\end{abstract}

Results: FT-IR spectra show that the drug and excipients were compatible with each other. The calculated F values found for WT, DT, and Q 15 were 045.559, 077.100 and 278.760, respectively. All Calculated F values are greater than tabulated values for all dependent variables. Prepared checkpoint was selected from its desirability value 0.935 and it gives a $100 \%$ drug release within 30 min.

Conclusion: These results confirm that the prepared HHC 25 mg IR layer is used for rapid control of hypertension.

Keywords: Bilayer tablet, $3^{2}$ Full factorial design, Immediate release, Hydralazine hydrochloride, Isosorbide dinitrate

(C) 2020 The Authors. Published by Innovare Academic Sciences Pvt Ltd. This is an open access article under the CC BY license (http://creativecommons.org/licenses/by/4.0/J DOI: http://dx.doi.org/10.22159/ijap.2020v12i5.38097. Journal homepage: https://innovareacademics.in/journals/index.php/ijap

\section{INTRODUCTION}

Hypertension affects around half of the adult population worldwide, being one of the most common cardiovascular disorders (CVD). It occurs when the high cardiac output exerts pressure on the arterial wall as the blood flow increases. The conventional dosage form used in the treatment of hypertension cannot produce the desired therapeutic effect for a prolonged period. The rationale for using fixed-dose combination therapy is to obtain increased blood pressure (BP) control by employing two antihypertensive drugs with different modes of action and enhance compliance by using a single tablet. Bilayer tablet is suitable for the sequential release of two drugs in combination, separate, and sustained release [1,2].

HHC, directly acting as a potent peripheral vasodilator, is widely prescribed in the treatment of hypertension and congestive heart failure by direct relaxation of arteriolar smooth muscle. While, ISDN is relaxation of vascular smooth muscle and consequent dilatation of peripheral arteries and veins, especially the later. Dilatation of the veins promotes peripheral pooling of blood and decreases venous return to the heart, thereby reducing left ventricular end-diastolic pressure and pulmonary capillary wedge pressure. The combination consists of HHC $25 \mathrm{mg}$ and ISDN $40 \mathrm{mg}$ fixed-dose that functions as a nitric oxide enhancer and an antioxidant that helps to prevent tolerance to the prolonged use of nitrate. This combination also balanced after-load and preload reduction with a lowering of ventricular filling pressure and systemic and pulmonic vascular resistance. The hemodynamic effects of the combination drug in heart failure include increased cardiac output $[3,4]$.

Aim of the present study was to develop and optimize the IR layer containing HHC $25 \mathrm{mg}$ using $3^{2}$ full factorial designs, to give immediate effect on direct relaxation of arteriolar smooth muscle.

\section{MATERIALS AND METHODS}

\section{Materials}

HHC was kindly supplied as gift samples by Torrent Pharmaceuticals, Ahmedabad, Gujarat India. ISDN was supplied as gift samples from Cadila Pharmaceuticals Ltd, Ahmadabad, India. Microcrystalline cellulose (MCC) was procured from Colorcon Asia Pvt. Ltd., Ahmedabad, Gujarat, India. Magnesium stearates, Talc, sodium starch glycolate (SSG), and croscarmellose sodium (CCS) were purchased from SD Fine Chemicals, Mumbai, India. All other materials and chemicals used were of either pharmaceutical or analytical grade.

\section{Drug-excipients compatibility study}

Drug excipient interaction plays a vital role in achieving the stability of the drug in dosage form. Fourier transform infrared spectroscopy (FT-IR) was used to study the physical and chemical interactions between drugs and excipients. FT-IR spectra of HHC and mixtures of drugs with other excipients were obtained by using the FT-IR instrument. (FT-IR-1700, Shimadzu, Kyoto, Japan) [5].

\section{Preliminary screening of super-disintegrating agent for IR layer}

The development of the IR layer containing HHC $25 \mathrm{mg}$ by selecting ingredients in the appropriate amount and the super-disintegrants optimized thereafter. The IR layer of HHC was prepared by the direct compression method. SSG, CCS, and ac-di-sol® were used in varying amounts as shown in table 1 . Batch T1 to T3 contained $2 \%$, $3 \%$, and $5 \%$ of SSG, respectively. Batch T4 to T6 contained $2 \%, 3 \%$, and $4 \%$ CCS, respectively and batch T6 to T10 contained 2\%, 3\%, $4 \%$, and $5 \%$ ac-di-sol ${ }^{\circledR}$ respectively. Prepared layer was evaluated for weight variation, thickness, hardness, friability, DT, WT, drug content, and $\mathrm{Q}_{15}[6,7]$.

Optimization of the super-disintegrating agent by using $3^{2}$ full factorial design

A $3^{2}$ full factorial designs were used for the optimization of the super disintegrating agent. The formulation of factorial batches as shown in table 2. Based on preliminary results, the amount SSG $\left(\mathrm{X}_{1}\right)$ and amount of ac-di-sol ${ }^{\circledR}\left(\mathrm{X}_{2}\right)$ were chosen as independent variables in $3^{2}$ full factorial designs, while WT $\left(\mathrm{Y}_{1}\right)$, DT $\left(\mathrm{Y}_{2}\right)$ and $\mathrm{Q}_{15}\left(\mathrm{Y}_{3}\right)$ were taken as dependent variables. Multiple linear regression analysis, 
ANOVA and graphical representation of the influence of factor by contour plots were performed using sigma plot $13.0[8,9]$. The experimental runs and measured responses of $3^{2}$ full factorial design batches of IR layer of HHC 25 mg were depleted in table 4 .

Table 1: Preliminary screening of super disintegrating agent for IR layer

\begin{tabular}{|c|c|c|c|c|c|c|c|c|c|c|}
\hline \multirow[t]{2}{*}{ Ingredients (mg) } & \multicolumn{10}{|c|}{ Qty. (mg/tab) } \\
\hline & T1 & T2 & T3 & T4 & T5 & T6 & T7 & T8 & T9 & T10 \\
\hline $\mathrm{HHC}^{*}$ & 25 & 25 & 25 & 25 & 25 & 25 & 25 & 25 & 25 & 25 \\
\hline MCC PH102 & 51 & 50 & 48 & 51 & 50 & 49 & 51 & 50 & 49 & 48 \\
\hline Tablettose & 20 & 20 & 20 & 20 & 20 & 20 & 20 & 20 & 20 & 20 \\
\hline SSG \# & 2 & 3 & 5 & 0 & 0 & 0 & 0 & 0 & 0 & 0 \\
\hline $\operatorname{CCS} \$$ & 0 & 0 & 0 & 2 & 3 & 4 & 0 & 0 & 0 & 0 \\
\hline Ac-Di-Sol® & 0 & 0 & 0 & 0 & 0 & 0 & 2 & 3 & 4 & 5 \\
\hline Magnesium stearate & 1 & 1 & 1 & 1 & 1 & 1 & 1 & 1 & 1 & 1 \\
\hline Talc & 1 & 1 & 1 & 1 & 1 & 1 & 1 & 1 & 1 & 1 \\
\hline Total & \multicolumn{10}{|c|}{$100 \mathrm{mg} / \mathrm{tab}$} \\
\hline
\end{tabular}

*HHC=hydralazine hydrochloride, "SSG = sodium starch glycolate, ${ }^{\$} \mathrm{CCS}=$ croscarmellose sodium

Table 2: Formulation of factorial design batches for IR layer

\begin{tabular}{|c|c|c|c|c|c|c|c|c|c|}
\hline \multirow[t]{2}{*}{ Ingredients (mg) } & \multicolumn{9}{|c|}{ Qty. (mg/tab) } \\
\hline & $F_{1}$ & $\mathbf{F}_{2}$ & $\mathbf{F}_{3}$ & $\mathbf{F}_{4}$ & $\mathbf{F}_{5}$ & $F_{6}$ & $\mathbf{F}_{7}$ & $\mathbf{F}_{8}$ & $\mathbf{F}_{9}$ \\
\hline $\mathrm{HHC}^{*}$ & 25 & 25 & 25 & 25 & 25 & 25 & 25 & 25 & 25 \\
\hline MCC PH102 & 49 & 48 & 47 & 48 & 47 & 46 & 47 & 46 & 45 \\
\hline Tablettose & 20 & 20 & 20 & 20 & 20 & 20 & 20 & 20 & 20 \\
\hline SSG \# & 2 & 3 & 4 & 2 & 3 & 4 & 2 & 3 & 4 \\
\hline Ac-Di-Sol $®$ & 2 & 2 & 2 & 3 & 3 & 3 & 4 & 4 & 4 \\
\hline Magnesium Stearate & 1 & 1 & 1 & 1 & 1 & 1 & 1 & 1 & 1 \\
\hline Talc & 1 & 1 & 1 & 1 & 1 & 1 & 1 & 1 & 1 \\
\hline Total & \multicolumn{9}{|c|}{$100 \mathrm{mg} / \mathrm{tab}$} \\
\hline
\end{tabular}

${ }^{*} \mathrm{HHC}=$ hydralazine hydrochloride, ${ }^{*} \mathrm{SSG}=$ sodium starch glycolate

\section{Development of bilayer tablet}

The bilayer tablets of IR layer HHC $25 \mathrm{mg}$ and SR layer ISDN $40 \mathrm{mg}$ were prepared separately and the two layers were compressed together. The IR layer of HHC was prepared using a direct compression method. The active ingredient, tablettose, MCC PH-102, and different super disintegrate mixed in a geometrically order. Magnesium stearate and talc added to the above blend. The whole blend passed through 40\# mesh and compressed using an $8 \mathrm{~mm}$ flat punch on a 12-station rotary tablet machine to form an IR layer [10, 11]. SR layer of ISDN also post optimized using $3^{2}$ full factorial designs and it was prepared using a direct compression method. The SR layer was compressed using a rotary tablet punching machine by using an 8 $\mathrm{mm}$ flat punch on a 12-station rotary tablet machine $[12,13]$.

\section{Evaluation of bilayer tablet}

The prepared tablets were evaluated for thickness, hardness, friability, and DT of the IR layer were evaluated as described by Nivedithaa VR et al., and Fridrun P et al. $[14,15]$.

Wetting time (WT): It was evaluated by using five circular tissue papers of $10 \mathrm{~cm}$ in diameter, which was placed in a petridish of 10 $\mathrm{cm}$ diameter. $10 \mathrm{ml}$ of eosin solution was adding to the petridish. A tablet was carefully placed on the surface of the tissue paper. The time-required water to reach the upper surface of the tablet was noted as the WT $[14,15]$.

HPLC was used for estimation of HHC and ISDN: The drug concentration was evaluated using reverse phase high-performance liquid chromatography. Analysis of the sample was performed using a cyberlab HPLC system equipped with a LCP-100 pump, cyber lab LC-UV100 UV detector, and RP C18 column $(250 \times 4.6 \mathrm{~mm} \mathrm{ID,}$ particle size $5 \mu$ ) at ambient temperature. The mobile phase used was a mixture of methanol and distilled water $1000 \mathrm{ml}$ containing $0.1 \mathrm{ml}$ TEA each (60: 40). The $\mathrm{pH}$ was adjusted to 6.5 . The flow rate was $1.0 \mathrm{ml}$ per min. The detection was carried out at $215 \mathrm{~nm}$. A calibration curve was plotted for HHC and ISDN. A good linear relationship was observed between the concentration of the drug and the peak area of the drug with a correlation coefficient [16].

Drug content for HHC: The drug content was determined by weighing 20 tablets from each batch and calculated the average weight. Then the tablets were triturated to get a fine powder. From the resulting triturate, the powder was weighed accurately, which was equivalent to $100 \mathrm{mg}$ HHC and dissolved in $100 \mathrm{ml}$ volumetric flask containing $100 \mathrm{ml}$ of $0.1 \mathrm{~N} \mathrm{HCl}$ and volume was made to $100 \mathrm{ml}$ with solvent. The volumetric flask was shaken using a sonicator for 1 h. and after suitable dilution with $0.1 \mathrm{~N} \mathrm{HCl}$. The drug content was determined using HPLC at $215 \mathrm{~nm}$.

In vitro drug release study: In vitro drug release of bilayer tablets was determined using a USP type-II dissolution test apparatus at $100 \mathrm{rpm}$. The dissolution was studied using $900 \mathrm{ml}$ of simulated gastric fluid $0.1 \mathrm{~N} \mathrm{HCl}$ (without enzyme, $\mathrm{pH} 1.2$ ) for the first $2 \mathrm{~h}$ and half dissolution model was followed for the sustained release layer for $12 \mathrm{~h}$. Filter through Whatman filter paper and replaced by an equal volume of dissolution medium sample were suitably diluted and analyzed by HPLC at $215 \mathrm{~nm}$.

Stability study: Optimized batch was packed in aluminum foil and was placed for stability study at $40^{\circ} \mathrm{C} / 75 \% \mathrm{RH}$ for 6 mo. The sample was evaluated after 6 mo for physical parameters and In vitro dissolution. The dissolution profile of the product was compared using the similarity factor, $\mathrm{f}_{2}$, which was calculated by the following formula.

$$
f_{2}=50 \log \left[\left\{1+\frac{1}{n} \sum_{t=1}^{n}\left(R_{t}-T_{t}\right)^{2}\right\}^{-0.5} x 100\right]
$$

Where a log is the logarithm to the base $10, \mathrm{n}$ is the number of time points, $\Sigma$ is the summation over all time points, $R_{t}$ is the mean dissolution value of the reference profile at time $t$ and $\mathrm{T}_{\mathrm{t}}$ is the mean dissolution value of the test profile at the same time point. The USFDA draft guidance document contains more information on the similarity factor $\left(f_{2}\right)$. The value of the similarity factor $\left(f_{2}\right)$ between 50 and 100 suggests that the two dissolution profiles are similar $[17,18]$.

\section{RESULTS AND DISCUSSION}

\section{Drug-excipients compatibility study by FT-IR}

Fourier transform infrared spectroscopy (FT-IR) was used to study the physical and chemical interactions between drugs and excipients. FT-IR spectra of HHC, and HHC with excipients were recorded using $\mathrm{KBr}$ mixing method on FT-IR instrument. The FT-IR spectra of the pure drug are shown in fig. 1(A). HHC exhibited peaks 
due to $\mathrm{C}=\mathrm{C}, \mathrm{N}-\mathrm{H}, \mathrm{C}=\mathrm{N}, \mathrm{C}-\mathrm{H}$, and $\mathrm{C}-\mathrm{C}$ stretching. The same peaks of the functional group remain unchanged with all the excipients individually, which was shown in fig. 1(B). Even the functional group shows no change with all the excipients together; all the peaks of major functional groups remain similar to the pure drug as formulation. So, from FT-IR spectra, we can conclude that the drug and excipients were compatible with each other and they were suitable to use for formulation [19].

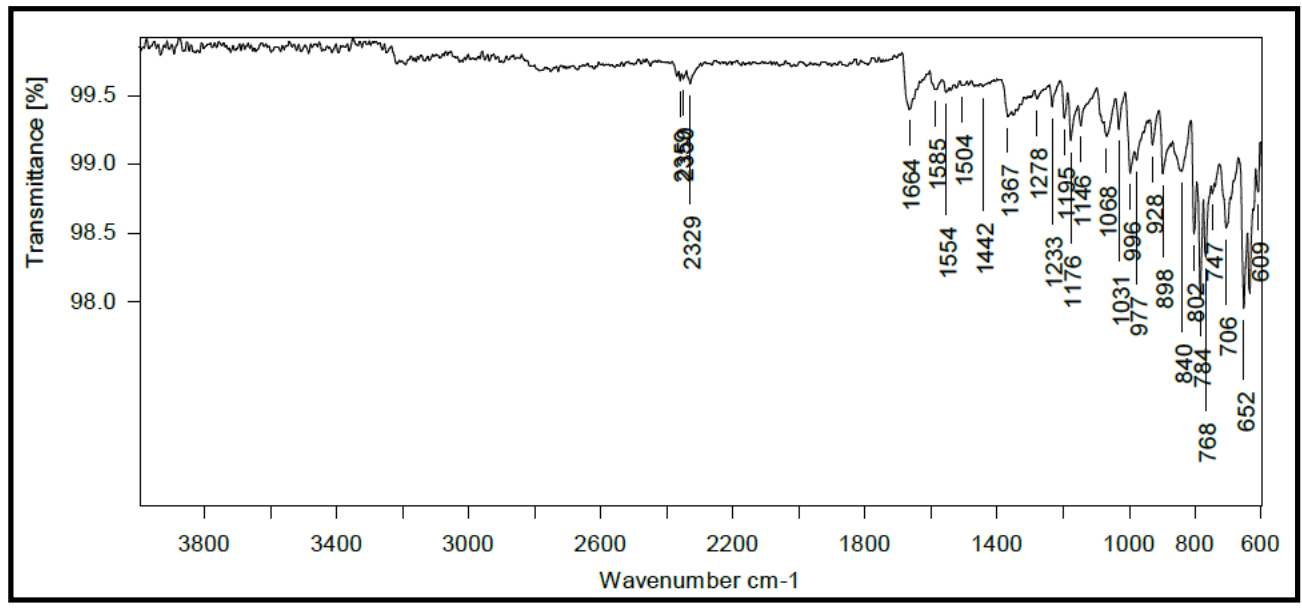

Fig. 1(A): FT-IR of HHC

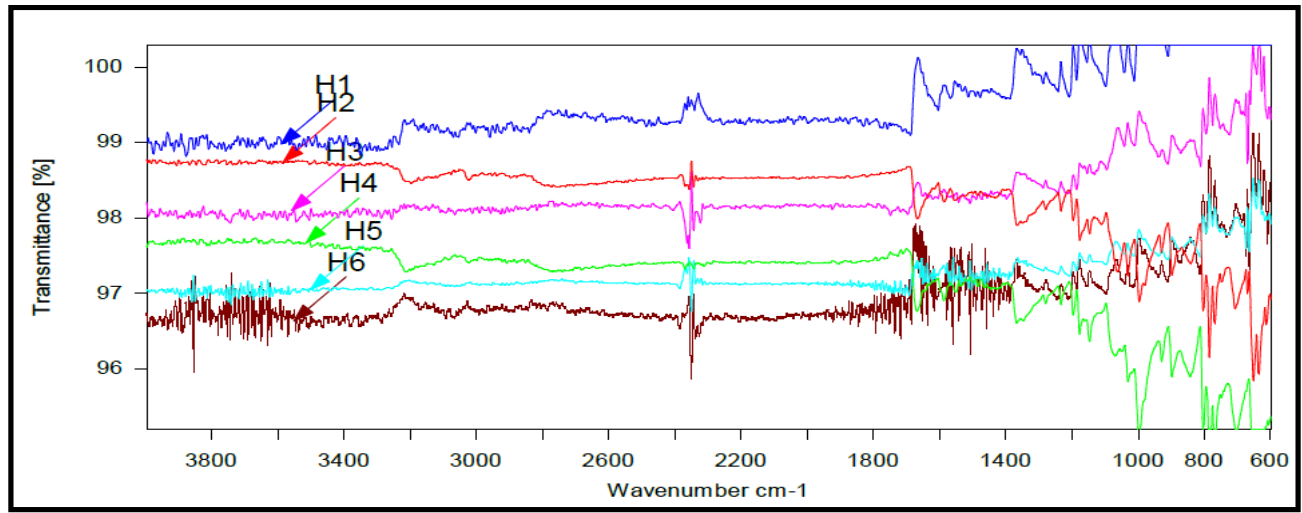

Fig. 1(B): Overlay Spectra of HHC with all excipients, (H1 = Pure HHC, H2 = HHC+MCC PH102, H3 = HHC+Tablattose, H4 = HHC+SSG, H5 = HHC+AC-Di-Sol $\left.{ }^{\circledR}, \mathrm{H6}=\mathrm{HHC}+\mathrm{CCS}\right)$

\section{Preliminary screening of super disintegrating agent for IR layer}

The batches T1-T10 were prepared to achieve an optimized concentration of super disintegrant and the most efficacious one among the three super disintegrants incorporated to prepare IR layer of HHC $25 \mathrm{mg}$ as shown by table 1 . Batch T1 to T3 containing SSG, among that batch T2 exhibited the lowest WT, DT, and more drug release was found as shown in table 3 . Above $5 \%$ of SSG increased DT and WT. This might be due to the reason that SSG swells in 3D. Batch T4-T6 was containing CCS, but it has shown higher WT, and DT compared to other batches. Batch T7 to T10 containing ac-di-sol $\circledast$ among that batch T9 depicted lowest WT, DT and more drug release was found but they do not achieve desired constraints. Hence, further trials were carried out by using a combination of SSG and ac-di-solß to understand their effect and optimize the concentration of both for the desired release profile [20].

Table 3: Preliminary screening of super disintegrating agent

\begin{tabular}{|c|c|c|c|c|c|c|c|c|}
\hline Batch & $\begin{array}{l}\text { Weight } \\
\text { variation (mg) }\end{array}$ & $\begin{array}{l}\text { Thickness } \\
\text { (mm) }\end{array}$ & $\begin{array}{l}\text { Hardness } \\
\left(\mathrm{Kg} / \mathrm{cm}^{2}\right)\end{array}$ & $\begin{array}{l}\text { Friability } \\
(\%)\end{array}$ & DT (s) & WT (s) & $\begin{array}{l}\text { Drug content } \\
(\%)\end{array}$ & $\mathbf{Q}_{15}$ \\
\hline T1 & $100.70 \pm 0.14$ & $2.55 \pm 0.04$ & $3.50 \pm 0.05$ & $0.43 \pm 0.02$ & $37 \pm 1$ & $28.10 \pm 0.06$ & $99.17 \pm 0.07$ & $75.4 \pm 2.81$ \\
\hline $\mathrm{T} 2$ & $100.70 \pm 0.05$ & $2.54 \pm 0.02$ & $3.10 \pm 0.04$ & $0.46 \pm 0.15$ & $36 \pm 2$ & $27.05 \pm 0.17$ & $98.58 \pm 0.04$ & $77.9 \pm 2.51$ \\
\hline T3 & $100.70 \pm 1.07$ & $2.54 \pm 0.04$ & $2.98 \pm 0.14$ & $0.46 \pm 0.03$ & $38 \pm 1$ & $28.06 \pm 0.04$ & $98.41 \pm 0.08$ & $77.3 \pm 1.25$ \\
\hline $\mathrm{T} 4$ & $100.10 \pm 0.45$ & $2.54 \pm 0.02$ & $3.60 \pm 0.11$ & $0.46 \pm 0.01$ & $44 \pm 1$ & $35.04 \pm 0.05$ & $99.17 \pm 0.06$ & $70.5 \pm 1.39$ \\
\hline T5 & $100.90 \pm 0.78$ & $2.57 \pm 0.05$ & $3.20 \pm 0.09$ & $0.47 \pm 0.06$ & $42 \pm 2$ & $34.05 \pm 0.09$ & $100.5 \pm 0.05$ & $72.3 \pm 1.15$ \\
\hline T6 & $100.40 \pm 0.34$ & $2.54 \pm 0.05$ & $2.98 \pm 0.07$ & $0.47 \pm 0.02$ & $41 \pm 2$ & $34.13 \pm 0.12$ & $102.4 \pm 0.09$ & $75.3 \pm 2.87$ \\
\hline $\mathrm{T} 7$ & $100.70 \pm 1.89$ & $2.54 \pm 0.03$ & $3.50 \pm 0.03$ & $0.46 \pm 0.02$ & $33 \pm 1$ & $27.14 \pm 0.14$ & $98.17 \pm 0.04$ & $81.4 \pm 2.44$ \\
\hline T8 & $100.50 \pm 0.22$ & $2.55 \pm 0.03$ & $3.12 \pm 0.05$ & $0.49 \pm 0.03$ & $32 \pm 1$ & $26.12 \pm 0.16$ & $98.48 \pm 0.17$ & $83.3 \pm 2.34$ \\
\hline T9 & $100.90 \pm 0.67$ & $2.56 \pm 0.04$ & $2.98 \pm 0.08$ & $0.49 \pm 0.02$ & $31 \pm 2$ & $23.10 \pm 0.14$ & $101.4 \pm 0.11$ & $86.9 \pm 1.46$ \\
\hline $\mathrm{T} 10$ & $100.80 \pm 1.35$ & $2.55 \pm 0.04$ & $2.97 \pm 0.08$ & $0.40 \pm 0.32$ & $33 \pm 1$ & $24.95 \pm 0.13$ & $102.5 \pm 0.13$ & $86.9 \pm 1.12$ \\
\hline
\end{tabular}

*All values are mean $\pm \mathrm{SD}(\mathrm{n}=6)$ 
Table 4: Runs and measured responses of $3^{2}$ factorial design batches

\begin{tabular}{|c|c|c|c|c|c|}
\hline Batch code & SSG $^{*}\left(\mathrm{X}_{1}\right)$ & Ac-di-sol@ $\left(\mathrm{X}_{2}\right)$ & WT (S) (Y) & DT (S) $\left(Y_{2}\right)$ & $Q_{15}\left(Y_{3}\right)$ \\
\hline $\mathrm{F}_{1}$ & -1 & -1 & $25.0 \pm 0.45$ & $31.10 \pm 0.17$ & $78.4 \pm 2.43$ \\
\hline $\mathrm{F}_{2}$ & 0 & -1 & $24.33 \pm 0.57$ & $29.20 \pm 0.29$ & $81.9 \pm 2.33$ \\
\hline $\mathrm{F}_{3}$ & 1 & -1 & $22.62 \pm 0.87$ & $28.23 \pm 014$ & $83.3 \pm 1.55$ \\
\hline $\mathrm{F}_{4}$ & -1 & 0 & $22.66 \pm 0.87$ & $30.34 \pm 0.27$ & $82.5 \pm 1.89$ \\
\hline $\mathrm{F}_{5}$ & 0 & 0 & $19.34 \pm 0.59$ & $28.54 \pm 0.24$ & $85.3 \pm 1.67$ \\
\hline $\mathrm{F}_{6}$ & 1 & 0 & $18.66 \pm 0.32$ & $26.34 \pm 0.17$ & $86.3 \pm 2.57$ \\
\hline $\mathrm{F}_{7}$ & -1 & 1 & $15.33 \pm 0.25$ & $26.54 \pm 0.14$ & $89.4 \pm 2.89$ \\
\hline $\mathrm{F}_{8}$ & 0 & 1 & $14.63 \pm 0.78$ & $24.43 \pm 0.27$ & $91.3 \pm 2.40$ \\
\hline $\mathrm{F}_{9}$ & 1 & 1 & $13.16 \pm 0.85$ & $23.46 \pm 0.89$ & $93.9 \pm 1.97$ \\
\hline \multicolumn{6}{|c|}{ Factors and the levels in the design } \\
\hline \multicolumn{3}{|c|}{ Independent variables } & $\operatorname{Low}(-1)$ & Medium (0) & High (1) \\
\hline \multicolumn{3}{|c|}{ Amount of SSG $*\left(X_{1}\right)$} & 2 & 3 & 4 \\
\hline \multicolumn{3}{|c|}{ Amount of ac-di-sol $\AA\left(\mathrm{X}_{2}\right)$} & 2 & 3 & 4 \\
\hline
\end{tabular}

*All values are mean $\pm \mathrm{SD}(\mathrm{n}=6),{ }^{*} \mathrm{SSG}=$ sodium starch glycolate, ${ }^{*} \mathrm{WT}=$ wetting time, ${ }^{\mathrm{D}} \mathrm{DT}=$ disintegration time, ${ }^{\$} \mathrm{Q}_{15}=$ In vitro drug release at $15 \mathrm{~min}$

Table 5: Evaluation of $3^{2}$ factorial design batches

\begin{tabular}{|c|c|c|c|c|c|c|}
\hline Batch & Hausner's ratio & Angle of repose $(\theta)$ & $\begin{array}{l}\text { Weight } \\
\text { variation (mg) }\end{array}$ & $\begin{array}{l}\text { Thickness } \\
\text { (mm) }\end{array}$ & Friability (\%) & Drug content (\%) \\
\hline $\mathrm{F}_{1}$ & $1.15 \pm 0.035$ & $22.54 \pm 0.02$ & $099.40 \pm 0.14$ & $2.56 \pm 0.04$ & $0.45 \pm 0.06$ & $99.17 \pm 0.05$ \\
\hline $\mathrm{F}_{2}$ & $1.14 \pm 0.015$ & $22.36 \pm 0.09$ & $100.60 \pm 0.07$ & $2.53 \pm 0.05$ & $0.44 \pm 0.05$ & $98.58 \pm 0.07$ \\
\hline $\mathrm{F}_{3}$ & $1.14 \pm 0.057$ & $22.38 \pm 0.09$ & $100.80 \pm 1.08$ & $2.54 \pm 0.07$ & $0.45 \pm 0.04$ & $99.41 \pm 0.06$ \\
\hline $\mathrm{F}_{4}$ & $1.16 \pm 0.05$ & $23.82 \pm 0.07$ & $099.50 \pm 0.56$ & $2.57 \pm 0.05$ & $0.47 \pm 0.07$ & $99.17 \pm 0.05$ \\
\hline $\mathrm{F}_{5}$ & $1.18 \pm 0.07$ & $23.38 \pm 0.06$ & $100.70 \pm 0.57$ & $2.58 \pm 0.04$ & $0.44 \pm 0.05$ & $100.5 \pm 0.07$ \\
\hline $\mathrm{F}_{6}$ & $1.12 \pm 0.071$ & $24.80 \pm 0.05$ & $100.90 \pm 0.78$ & $2.55 \pm 0.07$ & $0.47 \pm 0.03$ & $100.4 \pm 0.06$ \\
\hline $\mathrm{F}_{7}$ & $1.16 \pm 0.025$ & $23.81 \pm 0.03$ & $100.40 \pm 1.55$ & $2.55 \pm 0.06$ & $0.49 \pm 0.04$ & $99.17 \pm 0.05$ \\
\hline $\mathrm{F}_{8}$ & $1.16 \pm 0.025$ & $23.86 \pm 0.31$ & $099.40 \pm 0.67$ & $2.55 \pm 0.04$ & $0.46 \pm 0.06$ & $99.48 \pm 0.06$ \\
\hline $\mathrm{F}_{9}$ & $1.11 \pm 0.011$ & $23.85 \pm 0.07$ & $100.70 \pm 0.56$ & $2.53 \pm 0.06$ & $0.44 \pm 0.05$ & $99.54 \pm 0.07$ \\
\hline
\end{tabular}

*All values are mean $\pm \mathrm{SD}(\mathrm{n}=6)$

Table 6: Results of the ANOVA for dependent variables

\begin{tabular}{|c|c|c|c|c|c|}
\hline Source of variation & DF & SS & MS & F value & P value \\
\hline \multicolumn{6}{|l|}{$\mathbf{W T}^{*}$} \\
\hline Regression & 5 & 144.055 & 28.811 & 45.559 & 0.005 \\
\hline Residual & 3 & 1.897 & 0.632 & & \\
\hline Total & 8 & 145.952 & 18.244 & & \\
\hline \multicolumn{6}{|l|}{ DT \# } \\
\hline Regression & 5 & 057.111 & 011.422 & 077.100 & 0.002 \\
\hline Residual & 3 & 000.444 & 000.148 & & \\
\hline Total & 8 & 057.556 & 007.194 & & \\
\hline \multicolumn{6}{|l|}{$Q_{15} \$$} \\
\hline Regression & 5 & 193.583 & 038.717 & & \\
\hline Residual & 3 & 000.417 & 000.139 & 278.760 & $<0.001$ \\
\hline Total & 8 & 194.000 & 024.250 & & \\
\hline
\end{tabular}

${ }^{*} \mathrm{WT}=$ wetting time, ${ }^{\mathrm{D} T \mathrm{~T}}=$ disintegration time, ${ }^{\$} \mathrm{Q}_{15}=$ In vitro drug release at $15 \mathrm{~min}$

Table 7: Summary of regression output of factors for measured responses

\begin{tabular}{|c|c|c|c|c|c|c|c|c|}
\hline \multirow[t]{2}{*}{ Responses } & \multirow[t]{2}{*}{ Model } & \multicolumn{7}{|c|}{ Coefficient of regression parameters } \\
\hline & & $\mathbf{b}_{\mathbf{0}}$ & $\mathbf{b}_{1}$ & $\mathbf{b}_{2}$ & $\mathbf{b}_{11}$ & $\mathbf{b}_{22}$ & $\mathbf{b}_{12}$ & $\mathbf{R}^{2}$ \\
\hline \multirow[t]{2}{*}{$\mathrm{WT}^{*}$} & Full & 19.629 & 1.423 & 4.663 & 0.0567 & 0.663 & 0.365 & 0.987 \\
\hline & Reduced & 19.629 & 1.423 & 4.663 & & & & \\
\hline \multirow[t]{2}{*}{$\mathrm{DT}^{\#}$} & Full & 27.778 & -1.667 & -2.500 & 0.333 & 1.167 & 0.000 & 0.992 \\
\hline & Reduced & 27.778 & -1.667 & -2.500 & - & 1.167 & - & \\
\hline \multirow[t]{2}{*}{$\mathrm{Q}_{15^{\$}}$} & Full & 84.667 & 2.167 & 5.167 & 0.500 & 1.500 & 0.250 & 0.998 \\
\hline & Reduced & 84.667 & 2.167 & 5.167 & - & 1.500 & - & \\
\hline
\end{tabular}

${ }^{*} \mathrm{WT}=$ wetting time, ${ }^{\# \mathrm{DT}}=$ disintegration time, ${ }^{\$} \mathrm{Q}_{15}=$ In vitro drug release at $15 \mathrm{~min}$

$3^{2}$ Full factorial design model evaluation

A statistical model incorporating interactive and polynomial terms was used to evaluate the responses:

$$
\mathrm{Y}=\mathrm{b}_{0+} \mathrm{b}_{1} \mathrm{X}_{1}+\mathrm{b}_{2} \mathrm{X}_{2}+\mathrm{b}_{11} \mathrm{X}_{1}{ }^{2}+\mathrm{b}_{22} \mathrm{X}_{2}{ }^{2}+\mathrm{b}_{12} \mathrm{X}_{1} \mathrm{X}_{2}
$$

where, $\mathrm{Y}$ is the dependent variable, $\mathrm{b}_{\mathrm{o}}$ is the arithmetic mean response of the 9 runs and any bi is the estimated coefficients for the related factor $X_{i}$. The main effects $\left(X_{1}\right.$ and $\left.X_{2}\right)$ represent the average result of changing one factor at a time from its low to high value. The polynomial terms $\left(\mathrm{X}_{1}{ }^{2}\right.$ and $\left.\mathrm{X}_{2}{ }^{2}\right)$ are included to investigate nonlinearity. The interaction term " $\mathrm{X}_{1} \mathrm{X}_{2}$ " shows how the response changes when the two factors change simultaneously. Evaluation data for the IR layer of HHC $25 \mathrm{mg}$ were presented in table 4 and table 5. The fitted equations relating the responses that are, WT ( $\left.\mathrm{Y}_{1}\right)$ $\mathrm{DT}\left(\mathrm{Y}_{2}\right)$, and $\mathrm{Q}_{15}\left(\mathrm{Y}_{3}\right)$ to the transformed factor are shown in table 7 . 
The polynomial equations used to draw conclusions after considering the magnitude of coefficient and mathematical sign it carries (i.e. positive or negative). The results of ANOVA suggested that calculated F values for WT, DT, and $Q_{15}$ were $045.559,077.100$ and 278.760 , respectively, shown in table 6 . Tabulated $\mathrm{F}$ value was

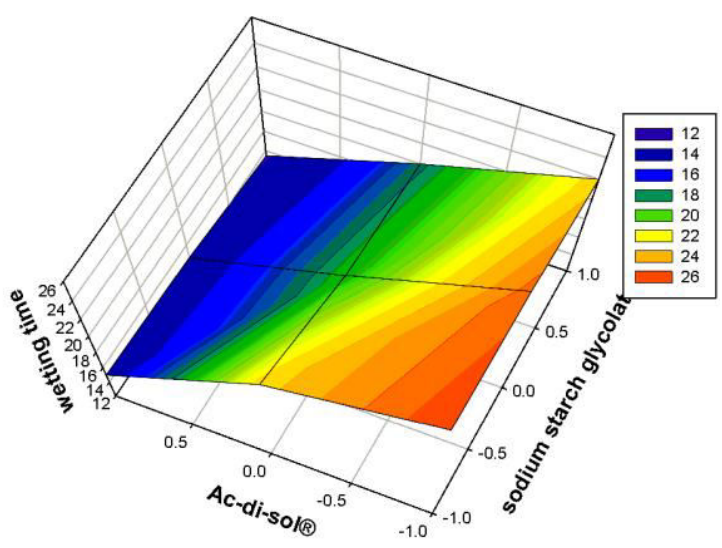

A found to be 9.013 at $\alpha=0.05$. Calculated $F$ values are greater than tabulated for all dependent variables. Therefore, the factors selected have shown significant effects. From the results of multiple regression analysis, it was found that all factors had a statistically significant influence on all dependent variables as $p<0.05[21,22]$.
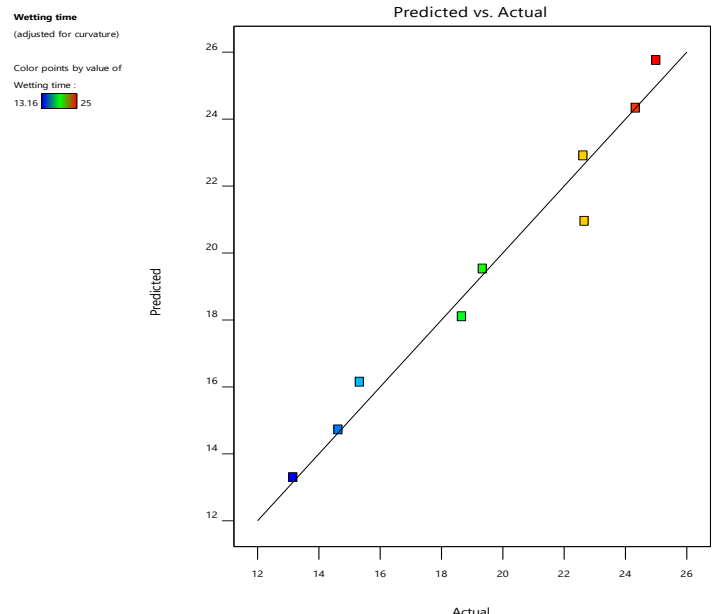

B

Fig. 2(A): 3D plot showing the effect of SSG and ac-di-sol ${ }^{\circledR}$ on WT (B) Predicted Vs actual value of WT

\section{Full and reduced model for WT}

$\mathrm{WT}=19.629-\left(1.423 * \mathrm{X}_{1}\right)-\left(4.663 * \mathrm{X}_{2}\right)+\left(0.0567 * \mathrm{X}_{1}^{2}\right)-(0.663 *$ $\left.\mathrm{X}_{2}^{2}\right)+\left(0.365 * \mathrm{X}_{1} \mathrm{X}_{2}\right)$

Based on the analysis of variance (ANOVA) the result showed that the developed linear model was highly significant, as was evident from a very low probability value 0.005 . The value of $\mathrm{R}^{2}$ was found to be 0.987 . The plot of observed WT versus predicted WT (fig. 2B) shows a straight line. Therefore, it may be concluded that the equation has good predictive ability. From the 3D plot (fig. 2A) and regression coefficient values of factors, it was concluded that when the amount of SSG and amount of ac-di-sol@ were increased WT was decreased. Due to the higher hydration capacity of ac-di-sol ${ }^{\circledR}$ it gives a faster WT compared to the SSG. For WT, the significance levels of the coefficients $b_{11}, b_{22}$, and $b_{12}$ were found to be $P=0.926$, 0.323 and 0.426 , respectively, so they were omitted from the full model to generate a reduced model. The reduced or the refined model for WT,

$$
\mathrm{WT}=19.629-\left(1.423 * \mathrm{X}_{1}\right)-\left(4.663 * \mathrm{X}_{2}\right)
$$

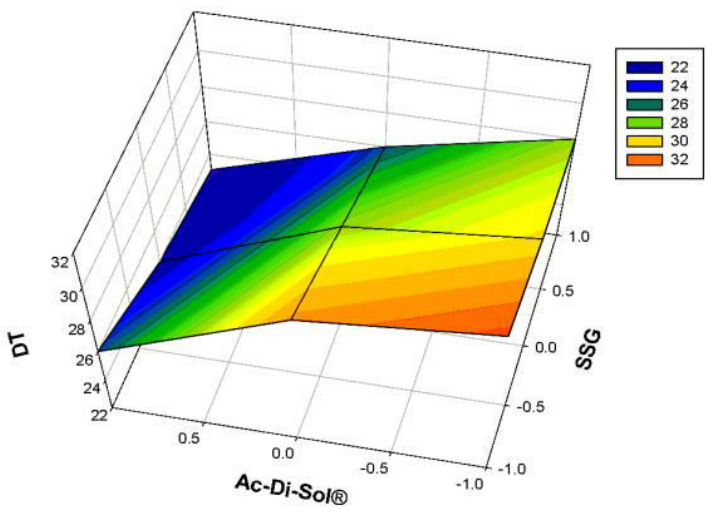

A

\section{Full and reduced model for DT}

$$
\begin{gathered}
\mathrm{DT}=27.778-\left(1.667 * \mathrm{X}_{1}\right)-\left(2.500 * \mathrm{X}_{2}\right)+\left(0.333^{*} \mathrm{X}_{1}{ }^{2}\right)-\left(1.167 * \mathrm{X}_{2}{ }^{2}\right)-(- \\
\left.0.000 * \mathrm{X}_{1} \mathrm{X}_{2}\right)
\end{gathered}
$$

Based on the analysis of variance (ANOVA) the result showed that the developed linear model was highly significant, as was evident from a very low probability value 0.002 . The value of $\mathrm{R}^{2}$ was found to be 0.992. The plot of observed DT versus predicted DT (fig. 3B) shows a straight line. Therefore, it may be concluded that the equation has the good predictive ability. From the 3D plot (fig. 3A) and the regression coefficient values of factors, it was concluded that when the amount of SSG and amount of ac-di-sol ${ }^{\circledR}$ were increased, disintegration time was decreased. The results also indicated that ac-di-sol@ was given a more significant effect on DT. Higher swelling capacity of ac-di-sol leads to faster disintegration compared to sodium starch glycolate. For DT, the significance levels of the coefficients $\mathrm{b}_{11}$ and $\mathrm{b}_{12}$ were found to be $\mathrm{P}=$ 0.308 and 1.000 , respectively, so they were omitted from the full model to generate a reduced model. The coefficients $b_{1}, b_{2}$, and $b_{22}$ were found to be significant at $\mathrm{P}<0.05$; hence, it was retained in the reduced model. The reduced or the refined model for DT,

$$
\mathrm{DT}=27.778-\left(1.667 * \mathrm{X}_{1}\right)-\left(2.500 * \mathrm{X}_{2}\right)-\left(1.167 * \mathrm{X}_{2}{ }^{2}\right)
$$

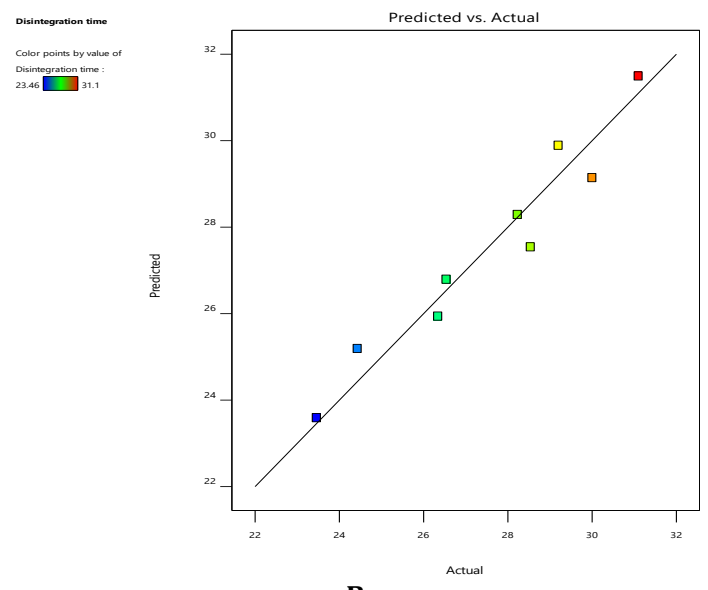

Fig. 3(A): 3D plot showing the effect of SSG and ac-di-sol® on DT (B) Predicted Vs actual value of DT 


\section{Full and reduced model for $\mathbf{Q}_{15}$}

$$
\begin{gathered}
\mathrm{Q}_{15}=84.667+\left(2.167 * \mathrm{X}_{1}\right)+\left(5.167 * \mathrm{X}_{2}\right)-\left(0.500 * \mathrm{X}_{1}{ }^{2}\right)+\left(1.500 * \mathrm{X}_{2}{ }^{2}\right)- \\
\left(0.250 * \mathrm{X}_{1} \mathrm{X}_{2}\right)
\end{gathered}
$$

Based on the analysis of variance (ANOVA) the result showed that the developed linear model was highly significant, as was evident from a very low probability value $<0.0001$. The value of $\mathrm{R}^{2}$ was found to be 0.998. The plot of observed $Q_{15}$ versus predicted $Q_{15}$ (fig. 4B) shows a straight line. Therefore, it may be concluded that the equation has good predictive ability. From the 3D plot (fig. 4A) and the regression
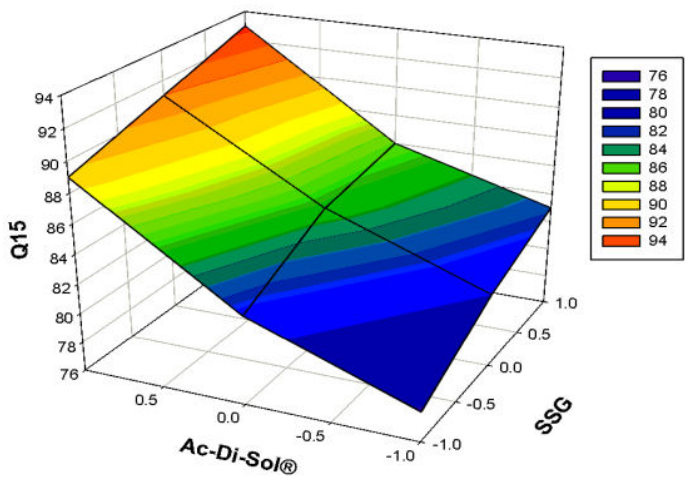

A coefficient values of factors, it was concluded that when the amount of SSG and amount of ac-di-sol ${ }^{\circledR}$ were increased that time, $Q_{15}$ was increased. The results also indicated that ac-di-sol $\AA$ was given a more significant effect on $Q_{15}$. For $Q_{15}$, the significance levels of the coefficients $b_{11}$ and $b_{12}$ were found to be $P=0.154$ and 0.272 , respectively, so they were omitted from the full model to generate a reduced model. The coefficients $b_{1}, b_{2}$ and $b_{22}$ were found to be significant at $\mathrm{P}<0.05$; hence, it was retained in the reduced model. The reduced or the refined model for $\%$ cumulative drug release,

$$
\mathrm{Q}_{15}=84.667+\left(2.167 * \mathrm{X}_{1}\right)+\left(5.167 * \mathrm{X}_{2}\right)+\left(1.500 * \mathrm{X}_{2}{ }^{2}\right)
$$
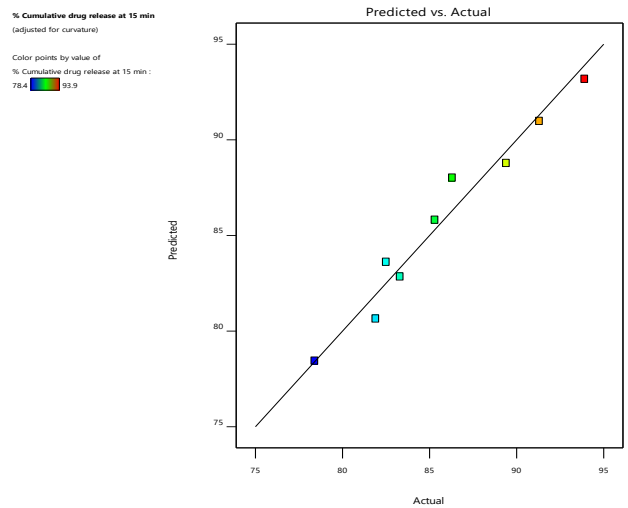

B

Fig. 4(A): 3D plot showing the effect of SSG and ac-di-sol ${ }^{\circledR}$ on $Q_{15}$ (B) Predicted Vs actual value of $Q_{15}$

\section{Search for the selection of optimized formulation}

The optimized IR layer containing HHC $25 \mathrm{mg}$ was identified by numerical optimization by selecting the desired ranges for the response variables as $\mathrm{WT}<16 \mathrm{~s}$, DT $<25 \mathrm{~s}$, and $\mathrm{Q}_{15}>90 \%$. Further, the optimized bilayer tablet formulation was demarcated in the design space overlay plot shown in fig. 5 . To validate the evolved mathematical models, a check-point was selected from its desirability value 0.935 . Check-point batch CP1 was prepared and evaluated. The observed and predicted values for batch CP1 as shown in table 8. A good correlation was found between observed and predicted values. Hence, it was concluded that the evolved models might be used for the theoretical prediction of responses within the factor space. Optimized IR layer gives a $100 \%$ drug release within $30 \mathrm{~min}$. It was kept for stability study and in vitro release profile at initial and after 6 mo was compared using similarity factor, $\mathrm{f}_{2}$, value which was found to be $91.50 \%$ for HHC. There is no significant difference in the similarity factor.

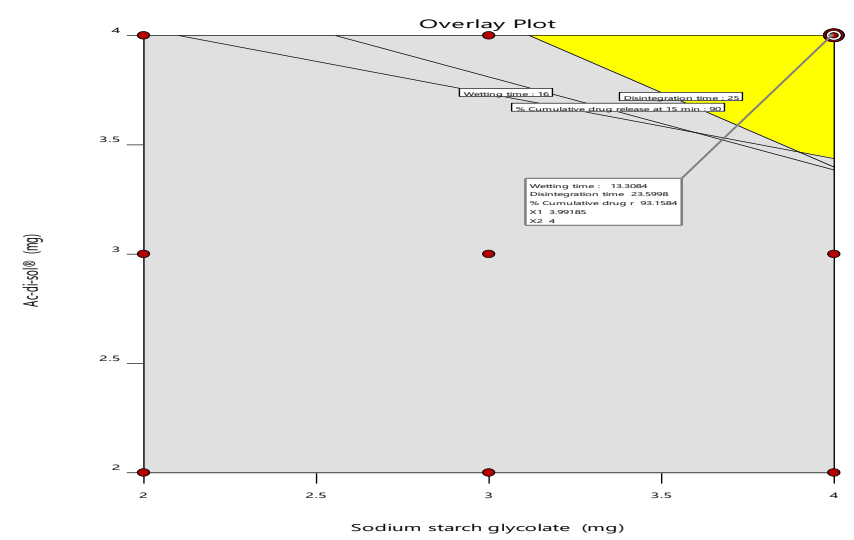

Fig. 5: Overlay plot depicting yellow color region design space and flagged point as the optimized IR layer containing HHC $25 \mathrm{mg}$

Table 8: Formulation and evaluation of checkpoint batches

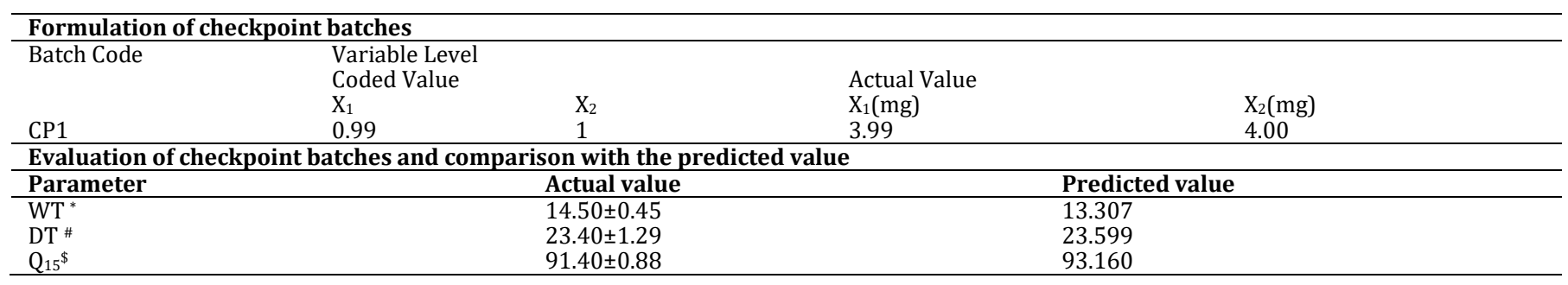

$(\mathrm{n}=6),{ }^{*} \mathrm{WT}=$ wetting time, ${ }^{\mathrm{D} T}=$ disintegration time, ${ }^{\$} \mathrm{Q}_{15}=$ In vitro drug release at $15 \mathrm{~min}$ 


\section{CONCLUSION}

The present investigation was to formulate, evaluate, and optimize the layer containing HHC in a bilayer tablet. There was no Drugexcipient interaction in the FT-IR study. From the results of preliminary studies SSG, $\left(\mathrm{X}_{1}\right)$ and the amount of ac-di-sol ${ }^{\circledR}\left(\mathrm{X}_{2}\right)$ were chosen as independent variables in $3^{2}$ full factorial designs while WT $\left(\mathrm{Y}_{1}\right)$, DT $\left(\mathrm{Y}_{2}\right)$ and $\mathrm{Q}_{15}\left(\mathrm{Y}_{3}\right)$ were taken as dependent variables. The effect of independent variables on dependent variables was studied by analyzing the response surface plot and polynomial equation. Optimization of the IR layer of HHC was performed by the overlay plot. A checkpoint batch was designed according to the results of the desirability value and evaluated for all the parameters. The results of the comparison of predicted response and obtained response were found in good agreement. The formulation was found to be stable during accelerated stability study. Quick disintegration and fast release of the HHC give a rapid control of hypertension. Further study was conducted for optimizing the SR layer containing ISDN 40 mg and compressed with the IR layer of HHC. The final formulation was decreasing the dosing frequency. It works as a nitric oxide enhancer and an antioxidant that helps to prevent tolerance to the prolonged use of nitrate.

\section{FUNDING}

Nil

\section{AUTHORS CONTRIBUTIONS}

All the authors have contributed equally.

\section{CONFLICT OF INTERESTS}

Declared none

\section{REFERENCES}

1. Jamie K, Rachael F, Katherine L, Tucker, Richard J, McManus. New approaches in hypertension management: a review of current and developing technologies and their potential impact on hypertension care. Curr Hypertens Rep 2019;21:1-8.

2. Taddei S. Combination therapy in hypertension: what are the best options according to clinical pharmacology principles and controlled clinical trial evidence? Am J Cardiovasc Drugs 2015;15:185-94.

3. Carmody MS, Anderson JR. BiDil (isosorbide dinitrate and hydralazine): a new fixed-dose combination of two older medications for the treatment of heart failure in black patients. Cardiol Rev 2007;15:46-53.

4. Cheng JW. A review of isosorbide dinitrate and hydralazine in the management of heart failure in black patients, with a focus on a new fixed-dose combination. Clin Ther 2006;28:666-78

5. Momin S, Khan S, Ghadage D, Yadav A, Wagh A. Formulation and evaluation of bilayer tablets of propranolol hydrochloride. J Drug Delivery Ther 2017:7:50-7.

6. D Radhika, A Mohaideen, Manoj KR, Bhanu PS, Jahan Nur, Rahman H. Development of bi-layer tablets for immediate and controlled release of allicin. Int J Curr Pharm Res 2017;9:153-60.
7. Harika R, S Dinesh Mohan, Alluri Ramesh, VRM Gupta. Formulation and in vitro evaluation of bilayer tablets of nebivolol hydrochloride and nateglinide for the treatment of diabetes and hypertension. J Drug Delivery 2015:1-14. DOI:10.1155/2015/827859

8. SN Politis, P Colombo, G Colombo, DM Rekkas. Design of experiments (DoE) in pharmaceutical development. Drug Dev Ind Pharm 2017;43:889-901.

9. Balaji R, Asra F, Babu MS. Formulation development and evaluation of immediate-release tablets of telmisartan. World J Pharm Pharm Sci 2017;6:659-73.

10. Kulkarni AMT, Aloorkar N. Application of novel natural polymer for controlling the release of fenoverine from controlled release matrix tablets. Int J Appl Pharm 2017;9:1-9.

11. Karad BB, Shinde AD. Formulation and evaluation of an immediate-release tablet of levonorgestrel. Indo Am J Pharm Res 2017;7:471-9.

12. Devender C, Dinesh K. Bilayer tablet tendered immediate release of paracetamol and sustained release of ibuprofen for quick onset of action against pain and fever. Asian J Pharm Clin Res 2019;12:166-74.

13. Kamble S, Poul B, Udapurkar P. Bilayer tablet of tramadol and gabapentin for combination pharmacotherapy of neuropathic pain: development and characterization. Int J Appl Pharm 2018;10:100-7.

14. Nivedithaa VR, Maanvizhi S. Formulation and evaluation of immediate-release combination tablet for cardiovascular diseases. Res J Life Sci Bioinf Pharm Chem Sci 2018;4:176-90.

15. Fridrun $P$. Theoretical and experimental investigations into the delamination tendencies of bilayer tablets. Int $\mathrm{J}$ Pharm 2011;408:102-12

16. Neelima K, Prasad YR. Analytical method development and validation for simultaneous estimation of Hydralazine, Isosorbide dinitrate in bulk and tablet formulation by RPHPLC. Int J Pharm Sci Res 2014;5:1290-4.

17. Kamble SR, Poul BN, Udapurkar PP. Fabrication and evaluation of bilayer floating tablet containing conventional ibuprofen and modified release pregabalin for combination pharmacotherapy of neuropathic pain. Asian J Pharm 2016;10:290-9.

18. Karim S, Bosu A, Biswas A, Laboni FR, Julie AS, Rashid MHO. Effect of sodium starch glycolate on the formulation of fexofenadine hydrochloride immediate-release tablets by direct compression method. J Sci Res 2018;10:31-8.

19. R Mazzeo, S Prati, M Quaranta, E Joseph, E Kendix, M Galeotti. Attenuated total reflection micro FTIR characterization of pigment-binder interaction in reconstructed paint films. Anal Bioanal Chem 2008;392:65-76.

20. Dnyaneshwar DG, Deshmukh MT, Solunke RS, Shete RV. Formulation and evaluation of antihypertensive bilayer tablet. Int J Pharm Sci Res 2019;10:4760-75.

21. Bolton S, Bon C. Pharmaceutical statistics: practical and clinical applications. $5^{\text {th }}$ ed. Informa Healthcare; 2005. p. 472-93.

22. Mandlik SK, Dandgavhal HP. Enhancement of skin permeability of econazole nitrate using novel flexisomal nanocarriers by implementing quality by design (QbsD) approach. Int J Appl Pharm 2019;12:123-33. 